\title{
DA EDUCAÇÃO EM CIÊNCIA ÀS ORIENTAÇÕES PARA O ENSINO DAS CIÊNCIAS: UM REPENSAR EPISTEMOLÓGICO
}

\section{From Science Education to Science Teaching: an epsitemological rethinking}

\author{
António Cachapuz \\ João Praia \\ Manuela Jorge
}

"Em qualquer aventura o que importa é partir, não é chegar".

Miguel Torga

\begin{abstract}
Resumo: No presente artigo, discute-se a construção epistemológica da Educação em Ciência como área interdisciplinar que integra, por apropriações e transposiçōes educacionais, campos relevantes do saber, nomeadamente a Filosofia da Ciência, a História da Ciência, a Sociologia da Ciência e a Psicologia Educacional. Desenvolvem-se, em seguida, argumentos de natureza curricular e de política educativa ${ }^{4}$ que procuram clarificar, afinal, para quê e para quem a Educação em Ciência.

Debruçamo-nos, necessariamente, por fim, sobre o ensino das Ciências e suas orientações preferenciais e que se perfilam como as mais congruentes com os referenciais teóricos enunciados. Note-se que esse percurso de pesquisa/teoria/prática exige reflexão, tempo, maturação de idéias, cumplicidade com a inovação e empenho na ação.
\end{abstract}

Unitermos: Educação em Ciência, Ensino das Ciências, Epistemologia

Abstract: The paper starts with a brief description of the epistemological construction of Science Education and its interdisciplinary character, in particular the contributions of the Philosophy of Science, History of Science, Sociology of Science and Educational Psychology. Secondly, arguments are developed in order to find out appropriate answers to two key educational issues, namely, the purpose of science education and who science education is for. Finally, the paper characterizes three main orientations for science teaching based on the previously developed framework.

Keywords: Science Education, Science Teaching, Educational Psychology

\section{Introdução}

A fazer fé no que nos diz Edgar Morin (1999), “... os séculos precedentes sempre acreditaram num futuro, fosse ele repetitivo ou progressivo. O século XX descobriu a perda do futuro, ou seja, a sua imprevisibilidade" (p. 79). E acrescenta que o conhecimento é, pois,

\footnotetext{
${ }_{1}^{1}$ Professor Catedrático, Departamento de Didáctica e Tecnologia Educativa, Universidade de Aveiro, Aveiro. Portugal. (e-mail: cachapuz@dte.ua.pt)

${ }^{2}$ Professor Associado com Agregação, Departamento/Centro de Geologia da Faculdade de Ciências da Universidade do Porto, Porto. Portugal. (e-mail:ifpraia@fc.up.pt)

${ }^{3}$ Assistente, Departamento de Educação e Psicologia, Universidade de Trás-os-Montes e Alto Douro, Vila Real. Portugal. (e-mail:manuelajorge@mail.telepac.pt)

${ }^{4}$ Em Portugal o Sistema Educativo organiza-se em três grandes ciclos: o Básico, o Secundário e o Superior. O Ensino Básico compreende o $1^{\circ}$ ciclo com quatro anos de escolaridade e o $2^{\circ}$ ciclo com dois anos. Quanto ao Ensino Secundário, abrange um ciclo de três anos $\left(7^{\circ}, 8^{\circ}\right.$ e $\left.9^{\circ}\right)$ e um outro igualmente de três anos $\left(10^{\circ}, 11^{\circ}\right.$ e $\left.12^{\circ}\right)$. O Ensino Superior compreende o Ensino Politécnico e o Ensino Universitário.
} 
"uma aventura incerta que comporta em si mesmo, permanentemente, o risco de ilusão e do erro" (p. 86). Ou seja, o autor chama-nos a atenção para o fato de que é preciso substituir a visão tradicional do conhecimento como algo estável e seguro por algo dotado de complexidade que tem de se adaptar constantemente a diferentes contextos e cuja natureza é incerta.

Importa sublinhar que a Sociedade do Conhecimento não é uma inevitabilidade histórica, ou seja, que a sua ocorrência não é guiada por qualquer determinismo histórico. Assim sendo, depende em boa parte de nós, como cidadãos e como professores, o sentido das transformaçōes que formos capazes de, responsavelmente, imprimir tendo em vista a formação de cidadãos cientificamente cultos. As transformaçōes que se sugerem no âmbito da Educação em Ciência (e muito particularmente na Ciência escolar) inscrevem-se precisamente nessa lógica de argumentos. Como é regra em estudos prospectivos, também este tem bem presente que o melhor modo de prever o futuro é ajudar a criá-lo.

Tem, pois, todo o sentido refletir primeiro na Educação em Ciência e só depois no Ensino das Ciências.

\section{Educação em Ciência: sua construção epistemológica}

A matriz do presente artigo tem um enfoque na construção epistemológica da Educação em Ciência (EC) enquanto quadro de referência para o Ensino das Ciências. ${ }^{5} \mathrm{Na}$ verdade, antes de abordarmos as orientaçōes para o Ensino das Ciências, é necessário clarificar qual o sentido da construção epistemológica da Educação em Ciência, no quadro de um novo diálogo inovador e coerente entre diferentes áreas do conhecimento. É o que sumariamente evidenciamos na figura 1. (Cachapuz et al., 2000).

No momento atual, na ausência de uma teoria geral que unifique e dê coerência a conceitos, fenômenos e circunstâncias relativas ao ensino, à aprendizagem e à formação foi necessário, na construção da Educação em Ciência, proceder a apropriaçôes de saberes pertinentes de outras áreas disciplinares. Diremos mesmo que não era possível à EC afirmar-se como área científica disciplinar em construção progressiva sem estar fortemente articulada com aqueles campos disciplinares. Mas tal processo de apropriação, ou seja, a natureza das transposições, não é indiferente. As transposiçōes não são projeçōes intradisciplinares das disciplinas de partida; ou seja, o quadro teórico final resultante dessas apropriaçōes envolve um processo de elaboração próprio à nova área de conhecimento (Educação em Ciência). Nem podia ser de outro modo já que importa que tal processo conduza a um todo autocoerente (quadro teórico de referência identitário) capaz de, tentativamente, dar respostas adequadas a problemas de ensino, aprendizagem e formação na sua globalidade concreta. Assim, por exemplo, não é auto coerente englobar num mesmo quadro de referência posiçôes epistemológicas pós-positivistas e posiçôes behavioristas sobre a aprendizagem. Por outro lado, uma vez que a interdisciplinaridade se constrói, no essencial, à custa de saberes disciplinares, o quadro teórico fica também dependente da maturidade epistemológica dessas mesmas disciplinas de partida; tenha-se em conta, por exemplo, o que se passa entre a Física (fase paradigmática) e a Psicologia da Aprendizagem (fase multiparadigmática). Tal dependência da cinética de maturação das disciplinas de partida pode gerar desfasamentos na coerência do quadro teórico resultante das apropriaçōes feitas.

Uma vez que a representação teórica resultante dessas apropriações disciplinares tem necessariamente um caráter interdisciplinar, ela traduz, na designação de Fourez (1995), uma ilha de racionalidade. No entender deste autor, é precisamente a capacidade de levar a cabo

\footnotetext{
${ }^{5}$ Importa referir que se trata de um modelo possivel e tentativo para a Educação em Ciência, ainda que possa traduzir, no presente, uma possibilidade heuristica que tende a expressar o "estado da Arte".
} 
abordagens interdisciplinares que deve estar no centro da promoção de uma cultura científica dos cidadãos. E daí a sua importância.

$$
\begin{aligned}
& \text { ex: psicologia da descoberta } \\
& \text { científica }
\end{aligned}
$$

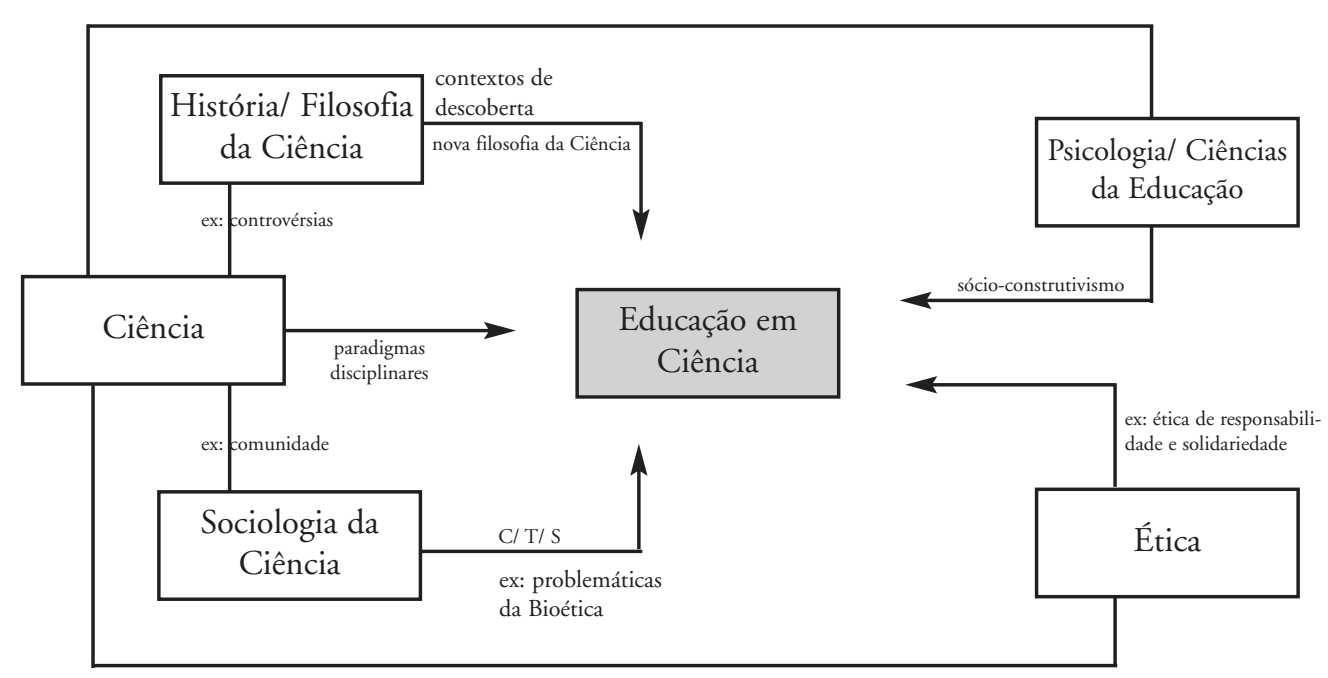

Figura 1. Caráter interdisciplinar da Educação em Ciência

$(\rightarrow)$ Apropriações / Transposiçôes Educacionais

Na figura 1, apresentam-se sob a forma de rede conceitual:

- exemplos de disciplinas/áreas disciplinares de partida que, não sendo as únicas relevantes para a construção da Educação em Ciência, são as mais relevantes (ver retângulos periféricos); uma importante conseqüência é que a lógica da construção da Educação em Ciência não coincide, nem sequer é dependente da lógica das Ciências da Educação; deve, contudo, haver um diálogo frutífero entre ambas;

- exemplos de articulações possíveis entre essas diferentes disciplinas/áreas disciplinares;

- exemplos de saberes de referência da Educação em Ciência, como resultado de apropriações das disciplinas de partida (setas); são estes saberes de referência, necessariamente "temperados" com as epistemologias das práticas de trabalho (em particular do trabalho docente), que estão no cerne da construção epistemológica da Educação em Ciência. É precisamente com base nestes saberes de referência que as orientações para o Ensino das Ciências que são propostas posteriormente ganham (tentativamente) o seu sentido, unidade e coerência.

As orientaçôes para o Ensino das Ciências são resultado da pesquisa e de uma mais aprofundada ligação entre o terreno onde se dá o seu desenvolvimento e os problemas com que a prática letiva se debate. A pesquisa deve, efetivamente, ser um dos esteios principais que dê coerência e sentido às tomadas de decisão que o professor, no seu cotidiano, tem de assumir de forma consciente e fundamentadamente. É a pesquisa com os professores, e não só sobre os professores, que transporta para o campo conceitual e para o campo da praxis os quadros de referência que deverão ser a base de uma fundamentação epistemológica - aberta a novas temáticas e disponível para integrar valores de contemporaneidade. 
Finalmente, um tal debate sobre o estatuto epistemológico da Educação em Ciência só tem verdadeiramente sentido educacional se estiver articulado com a questão da justificação social da Educação em Ciência, questão esta com profundas consequiências. A questão nuclear passa por termos de rever respostas sobre o para quê e não só sobre o o quêe (questão ligada aos currículos) e o como (questão ligada às estratégias de trabalho), como quase sempre sucede e, apesar de tudo, requerendo respostas bem menos comprometedoras. Grande parte das convulsões de muitos sistemas educativos, nos últimos anos, passa por aqui (em particular no que respeita ao ensino secundário, isto é, questionando para que é ele serve). Se não formos capazes de encontrar novas respostas adequadas não só não seremos capazes de entusiasmar mais jovens para estudos científicos como também a compreensão e utilidade social do esforço científico/tecnológico ficarão prejudicadas. $\mathrm{O}$ fosso entre as elites científicas e cidadãos cientificamente analfabetos alargar-se-á.

\section{Educação em Ciência: para quem e para quê??}

De acordo com o Memorando sobre Aprendizagem ao Longo da Vida, elaborado pela Comissão Européia em 2000 em Lisboa, duas das seis mensagens prospectivas aí expressas em matéria de aprendizagem dizem o seguinte:

Mensagem 1: "Novas competências básicas para todos" e cujo objetivo é "Garantir acesso universal e contínuo à aprendizagem, com vista à aquisição e renovação das competências necessárias à participação sustentada na sociedade do conhecimento". Mensagem 3: "Inovação no ensino e na aprendizagem" e cujo objetivo é "Desenvolver métodos de ensino e aprendizagem eficazes para uma oferta contínua de aprendizagem ao longo da vida e em todos os domínios da vida". Trata-se, sem dúvida, de objetivos ambiciosos.

A primeira das mensagens referidas vem recolocar a questão central do para quem a Educação em Ciência. A tônica da segunda mensagem já tem a ver com o como do ensino e da aprendizagem das Ciências.

A questão do para quem uma educação científica, tal como muitas vezes sucede na discussão de problemáticas educacionais, só aparentemente é evidente; talvez por isso mesmo, não tem sido suficientemente debatida. Em Portugal, pelo menos ao nível do ensino formal e obrigatório, a Educação em Ciência já é para todos. A questão é outra. Deve colocar-se ao nível da justificação social das finalidades educativas e, por isso mesmo, o para quem está estreitamente articulada à questão do para quê.

Milner (1986) aponta critérios: "só tem sentido colocar no currículo uma dada área do conhecimento, se conseguirmos demonstrar três ordens de argumentos: a primeira, é de que essa área contribui com conhecimentos, competências e perspectivas que mais nenhuma outra permite; a segunda, é de que esses aspectos não podem ser adquiridos informalmente, mas sim via instrução formal; a terceira, é de que é importante e tem valor adquirir tais conhecimentos, competências e perspectivas". Comentando estes argumentos, no caso da presença da Ciência no currículo, Millar (1996) considera que o primeiro e o segundo não são polêmicos. Na verdade (primeiro argumento), a Ciência tem não só um objeto bem definido, nomeadamente a nível do mundo natural, mas utiliza abordagens e metodologias específicas (embora nem sempre fáceis de definir em detalhe). Por outro lado (segundo argumento), bastaria a problemática das concepçôes intuitivas dos alunos para justificar o estudo formal da Ciência no currículo. $\mathrm{O}$ terceiro argumento é já mais polêmico, para o autor.

No nosso entender, a resposta à pergunta do para quêe é mais sério desafio que temos pela frente. Como refere Chassot (2000) a Educação em Ciência deve dar prioridade à formação de cidadãos cientificamente cultos, capazes de participar ativamente e responsavelmente em 
sociedades que se querem abertas e democráticas. Prioridade, não exclusividade. Esclareça-se desde já que o sentido que aqui se dá a "cientificamente culto" vai ao encontro do expresso por Hodson (1998) ou seja, um conceito multidimensional envolvendo simultaneamente três dimensões: aprender Ciência (aquisição e desenvolvimento de conhecimento conceitual); aprender sobre Ciência (compreensão da natureza e métodos da Ciência, evolução e história do seu desenvolvimento bem como uma atitude de abertura e interesse pelas relações complexas entre Ciência, Tecnologia, Sociedade e Ambiente); aprender a fazer Ciência (competências para desenvolver percursos de pesquisa e resolução de problemas). Registre-se que o aprofundamento de tais dimensões não é naturalmente o mesmo quando se trata da formação de futuros especialistas (em particular cientistas) ou na óptica da educação para a cidadania. De igual modo, e no âmbito do ensino formal, o aprofundamento não é naturalmente o mesmo em diferentes níveis de ensino.

Refira-se, no entanto, que vários autores (por exemplo, Collins, 1999; Shamos, 1995) levantam questões pertinentes sobre os verdadeiros mecanismos de decisão usados pelo vulgar dos cidadãos quando da apreciação de determinadas problemáticas científico/tecnológicas, considerando que freqüentemente a complexidade das situações exige que tais decisões sejam entregues a peritos. Assim, por exemplo, Collins refere a conhecida polêmica sobre a verossimilhança da fusão fria descoberta por Martin Fleischam e sua potencial implicação na política energética defendida por diferentes partidos políticos nos Estados Unidos da América, colocando a questão de que é que o público precisa saber para votar? E recorda que, mesmo entre os cientistas, as opiniões estavam divididas, sugerindo que aquilo que o público precisa compreender é a natureza do saber dos peritos, ou seja, o processo através do qual o conhecimento científico/tecnológico é gerado e não o conteúdo desse conhecimento. No nosso entender, subjacente a esta visão está o conhecido modelo de déficit de conhecimento, tão caro à comunidade científica. Se é certo que seria ingênuo pretender tornar cada cidadão num Leonardo de Vinci da era moderna (!) também não é menos certo que o estudo de situações concretas recentes em Portugal, e de que a co-incineração de resíduos ou a polêmica sobre o papel de munições com urânio empobrecido na morte de soldados nos Balcãs, mostram as limitaçôes de um tal modelo. Hoje em dia, muitas das problemáticas científico/tecnológicas (porventura as mais importantes) são de uma grande complexidade e envolvem no processo de debate e decisão nomeadamente vertentes políticas, econômicas e sociais. Como se refere (Ziman, 1999), tal complexificação reflete um novo ethos da Ciência que passou de um modo dominante de trabalho de Ciência Acadêmica para um modo dominante de trabalho de Ciência Industrial, sobretudo após a Segunda Guerra Mundial.

A questão interessante que se coloca é acerca de quais os saberes que todo o cidadão deve adquirir, questão cuja resposta é certamente polêmica e complexa, mas que só se torna impossível se adotarmos desde logo uma atitude de resignação.

Em primeiro lugar, para se ser cientificamente culto, não basta a aquisição de conhecimentos e competências tradicionalmente apresentadas de jure nos currículos de Ciências, desde cedo orientados, de fato, para quem pretende seguir futuros estudos de Ciências (ainda que a maioria dos alunos não o faça). Ser cientificamente culto implica também atitudes, valores e novas competências (em particular, abertura à mudança, ética de responsabilidade, aprender a aprender...) capazes de ajudar a formular e debater responsavelmente um ponto de vista pessoal sobre problemáticas de índole científico/tecnológica, juízos mais informados sobre o mérito de determinadas matérias e situações com implicações pessoais e/ou sociais, participação no processo democrático de tomada de decisões, uma melhor compreensão de como idéias da Ciência/Tecnologia são usadas em situações sociais, econômicas, ambientais e tecnológicas específicas. 
Em segundo lugar, a orientação e eventual seleção de alunos que desejam ser futuros especialistas deve ser feita de um modo completamente diferente do atual. Deve ser feita a partir de uma população entusiasta de alunos, tendo já obtido com sucesso uma cultura científica/tecnológica geral. E para os que não pretendem seguir estudos científicos, deveria ser dada a oportunidade (quer no ensino secundário quer no ensino superior) de poderem freqüentar uma área interdisciplinar de "Estudos de Ciência" onde pudessem acompanhar e aprofundar, de forma necessariamente mais qualitativa e valorizando o desenvolvimento pessoal dos alunos e o debate de problemáticas Científico/Tecnológicas contemporâneas. A decisão de "até onde" deve ter lugar a Educação em Ciência para uma cultura científica geral é essencialmente política (a escolaridade obrigatória em Portugal tende já para os 12 anos de escolaridade, ou seja, em breve será a futura "escola primária"). O que importa aqui é vincar uma outra filosofia de trabalho em que se redefinem prioridades e suas conseqüências em relação à configuração da Educação em Ciência.

Em terceiro lugar, a ênfase da Educação em Ciência na escolaridade obrigatória (que é, pois, para todos) deve ser centrada no aluno (sobretudo para os mais pequenos) e na sociedade. Daí que pensemos que não tem sentido o estudo das disciplinas de per si como atualmente ainda acontece, quer de forma explícita, quer de forma implícita (embora nem sempre se designem como tal). Na escolaridade obrigatória, e no quadro de uma cultura científica/tecnológica geral, os saberes relativos às disciplinas devem ser aprendidos através do estudo de temáticas inter/transdisciplinares, eventualmente situaçōes problema, explorando designadamente a perspectiva PBL (problem based learning), e não através do estudo de conceitos e princípios isolados centrados na estrutura lógica das disciplinas, com algumas aplicaçôes à mistura (que curiosamente são muitas vezes por onde se poderia, mais vantajosamente, começar percursos de ensino!). Por outro lado, o estudo de tais temáticas não deve partir de uma visão infantilizante das capacidades de aprendizagem dos alunos. Há que ter em conta a possibilidade de alunos academicamente mais motivados. Assim, tanto quanto possível, é necessário que o currículo (e a sua gestão) adote enfoques gradualistas de dificuldade crescente, em particular pela exploração das potencialidades oferecidas pelas novas tecnologias da informação e comunicação na individualização do ensino. Em Portugal, por exemplo, faltam projetos de inovação curricular centrados nesta direção.

O que importa fomentar, e desde o início da escolaridade, é a curiosidade natural dos alunos e o seu entusiasmo pela Ciência/Tecnologia e, para tal, uma perspectiva sistêmica do conhecimento é a mais indicada. Em particular, para os mais novos, trata-se de explorar os seus saberes do dia a dia como ponto de partida, já que é por aí que os alunos mais facilmente podem reconhecer os contextos e história pessoal a que eventualmente estão ligados e, conseqüentemente, aumentar a sua motivação. Trata-se pois de contextualizar e humanizar a Ciência escolar (não confundir com banalizar) para que mais facilmente e mais cedo se desperte o gosto pelo seu estudo. Uma tal abordagem implica uma disponibilidade científica acrescida por parte dos professores. $\mathrm{O}$ tipo de transposiçōes didáticas que ela pressupōe exige elevada competência científica e didática aos professores. Nos anos terminais do ensino secundário, a ênfase já deve ser na preparação para futuros estudos científicos, o que não quer dizer um ensino acadêmico seguindo uma lógica estritamente disciplinar (exceto no ensino superior) nem um ensino livresco.

Quem tem a responsabilidade de elaborar os currículos (dos ensinos básico e secundário) ainda não levou a sério que o eventual entusiasmo dos alunos por estudos de Ciência não decorre nem naturalmente nem inevitavelmente, como que por contágio, dos sucessos científico/tecnológicos. $\mathrm{O}$ caráter acadêmico e não experimental que marca em grau variável os currículos de Ciências e o seu ensino (nos ensinos básico e secundário) é, porventura, o maior responsável pelo desinteresse dos jovens alunos por estudos de Ciências. A Ciência que se legitima nos currículos está desligada do mundo a que, necessariamente, diz respeito. 
Alguma coisa tem de mudar nos currículos e no ensino das Ciências se quisermos motivar os alunos. Recorrendo à conhecida "equação" de Vroom (1964), Motivação = Valor x Expectativa, o que se passa atualmente é que, lido pelos olhos dos alunos, o primeiro termo (Valor) é freqüentemente nulo já que só estamos motivados para aprender aquilo que valorizamos. Nesse caso o produto também será nulo. Quanto ao segundo termo, tendo a ver com o sucesso que se espera ter das aprendizagens, é dificilmente conciliável com a Escola de insucesso que temos.

Tudo se passa como se os responsáveis pelas políticas educativas não tivessem tido em devida conta: (a) a envolvente sócio-cultural em que a educação tem hoje lugar (b) uma adequada cultura pedagógica no que respeita à aprendizagem. Ambos os aspectos concorrem para criar uma falsa representação dos alunos sobre a (aparente) facilidade do processo de aprendizagem.

Na verdade, e no que respeita ao primeiro aspecto acima referido (a), "temos de nos lembrar que os alunos dos anos 50 eram muito mais condescendentes, eram oriundos de ambientes familiares estáveis, não tinham sido expostos à cultura Pop e quase não viam televisão" (Osborne, 1992). A questão não é só ver televisão mais tempo; poderia até ser aconselhável aumentar o tempo médio de visionamento (em Portugal, cerca de 3,5 h/dia, em média); a verdadeira questão é o que se vê e o entendimento que se tem do que se vê. Com efeito, estamos ainda longe de poder apreciar todo o impacto da comunicação de massas, a começar pela televisão, no que respeita à promoção de uma cultura de análise e reflexão que uma cultura científica pressupõe. Como lucidamente refere Ramonet (1999), "Os media ao sacrificar à ideologia do direto e do instantâneo, reduzem o tempo de análise e de reflexão. Assim, são as sensações que tomam a primazia... É neste quadro que a 'equação' ver = compreender, adquire todo o seu sentido e amplitude. No entanto, desde o século XVIII a racionalidade moderna, com o século das Luzes e a revolução científica, desenvolveu-se precisamente contra esta idéia” (p. 88). Ou seja, ver NÃO é compreender. Palavras sábias as de Ramonet, que remetem para a diferença entre informação (científica) e conhecimento (científico); a primeira como algo que é cada vez mais "oferecido" (resolvida a eventual questão democrática do seu acesso) e o segundo como algo que é pessoal e socialmente construído. Foi preciso a avalanche de informações dos mais diversos tipos e pelos mais diversos meios com que somos confrontados para se perceber melhor que a informação não é senão uma condição necessária do conhecimento. Esta é, aliás, uma diferença que não está resolvida para muitos alunos e que, por isso mesmo, criam falsas expectativas sobre a aparente facilidade da sua própria aprendizagem. Porventura a mais perversa é de que a construção do (seu) conhecimento é tão fácil como aceder, hoje em dia, à informação por meio do simples pressionar de uma tecla. O segundo ponto acima referido (b), pretende chamar a atenção para que, cumulativamente a este tipo de representações dos alunos sobre a sua própria aprendizagem, existe uma certa cultura pedagógica de facilitismo em relação à aprendizagem, confundindo-se o prazer de sabermos mais qualquer coisa com a dificuldade de chegarmos até lá. Ou seja, ao contrário de pedagogias do facilitismo, aprender exige (entre outras coisas) esforço, perseverança, empenho e sacrifícios. Aprender Ciências, em que o mais das vezes implica romper com o senso comum (caráter contra-intuitivo), porventura exige ainda mais cuidados com a nossa própria aprendizagem.

Refira-se, finalmente, que não é só uma certa cultura de facilidade em relação à aprendizagem das Ciências que assim se pode instalar nos alunos. Através da televisão legitima-se também a sobrevalorização do conhecimento meramente factual (sobretudo por meio de prêmios de grande valor nos concursos televisivos). O que se legitima nesses concursos é o conhecimento dos participantes sobre o que, quem, qual, e quando. Não se valoriza o como, muito menos o porquê. Deste modo, a televisão reforça o enciclopedismo (precisamente o menos importante na era digital), sacrificando a reflexão crítica à pretensão de objetividade. O conhecimento coisificou-se, transformou-se em mercadoria, trocou-se por uma batedeira elétrica, viagem intercontinental, ou 
automóvel... Como acima se referiu, a questão não é só deixarmos de ver televisão (ainda que em alguns casos fosse um ato de sanidade mental). A resposta possível é um outro diálogo entre a educação formal e a educação não formal, para não ficarmos desarmados perante a informação que nos entra pela casa/sala de aula dentro. Tal diálogo passa, necessariamente, por metodologias e estratégias de ensino inovadoras em que freqüentemente a televisão passa a ser um recurso didático não só com a finalidade tradicional de, através da imagem, tornar o discurso didático/pedagógico mais atraente e motivante para os alunos, mas também visando a análise crítica da própria informação veiculada; a cooperação entre professores de Ciências e de outras áreas disciplinares, a começar pelas Ciências Sociais e Humanas adquire aqui todo o seu sentido. É, afinal, de outra Escola que aqui se fala.

\section{Orientações para o ensino das Ciências}

Tendo como suporte os elementos de referência desenvolvidos sobre a Educação em Ciência (fig.1), ilustra-se tentativamente na fig. 2 as orientaçôes deles decorrentes para o ensino das Ciências e seus cruzamentos. Mais importante do que olhar para essas orientaçôes separadamente, interessa estar atento ao modo como estas orientaçôes (e respectivas dimensões) se cruzam e interagem harmoniosamente no âmbito do ensino das Ciências.

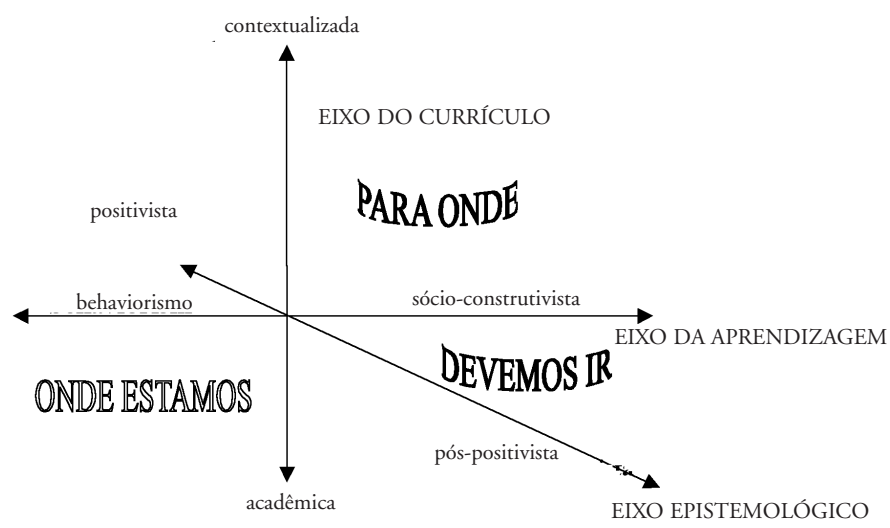

Figura 2.Três dimensōes da Ciência escolar

\section{Orientação $\mathrm{n}^{\circ} 1$ - Dimensão pós-positivista}

Adquirir conhecimentos científicos não leva necessariamente à compreensão de como a Ciência funciona. O que os alunos aprendem, hoje em dia, de Ciência é uma retórica de conclusões. Precisamente o que a Ciência não é!

O entendimento da natureza da Ciência que aqui se defende vai bem mais além do que o Positivismo lhe conferiu e insere-se nas linhas mestras da designada Nova Filosofia da Ciência (Abímbola, 1983). O conceito tradicional de Ciência como uma natureza autônoma (internalista) e com uma legalidade que se impõe de forma absoluta, do exterior aos seres e às coisas, de sentido autoritário, reducionista e determinista, não tem mais sentido. Defendemos, assim, um posicionamento pós-positivista sobre a Ciência, aqui entendido como valorizando a índole tentativa do conhecimento científico, envolvendo sempre, de algum modo, na sua construção, uma confrontação com o mundo, dinâmico, probabilístico, replicável e humano (isto é, feita por Homens e para 
Homens), não confundindo a procura de mais verdade com a busca "da" verdade (como se de um absoluto se tratasse). Atualmente, a Ciência é parte inseparável de todas as outras componentes que caracterizam a cultura humana tendo, portanto, implicações tanto nas relações Homem-Natureza como nas relações Homem-Homem.

Perfilhar uma visão pós-positivista de Ciência não significa cair na armadilha do relativismo ingênuo (relativismo epistêmico naturalmente, já que sobre o relativismo estético os consensos são mais fáceis) pelo que este acarreta de banalização do conhecimento científico (a Ciência como mera construção sociocultural a par, por exemplo, da Astrologia ou Quiromancia). O desenvolvimento deste debate ultrapassa os limites deste trabalho (ver por exemplo, Cachapuz et al., 2001). Refira-se, no entanto, que, um dos aspectos essenciais que está em jogo no relativismo ingênuo, não é somente que o que é considerado existir (por exemplo, o vírus HIV) depende do conhecimento de que uma dada cultura dispóe e dos processos de que dispõe para construir tal conhecimento. Contudo, podem algumas culturas (ver por exemplo o que se passa hoje em dia em alguns países de África) não acreditar que o(s) vírus HIV existe(m); quer acreditem ou não na existência de vírus HIV (em acordo com a sua cultura), eles existem mesmo (com as conseqüências que se conhecem). Em Ciência temos sempre, de algum modo, de nos confrontar com o real. Persiste assim uma grande confusão entre Ciência como mera construção sociocultural e Ciência como projeto social e culturalmente contextualizado (que é o que ela é). A diferença não é só de grau. É também epistêmica. No pólo oposto, isto é, no quadro do realismo ingênuo (que o Positivismo legitimou), não juramos de pé juntos que existem mesmo buracos negros ou o bosão de Higgs. Até ver.

Esta banalização do conhecimento científico está implícita em versões radicais do construtivismo epistemológico e de que Glasersfeld (1993) é um conhecido exemplo, estabelecendo uma ruptura entre o epistêmico e o ontológico (ou até ignorando este). Tal ruptura é infeliz e não serve a Educação em Ciência. No nosso entender, o posicionamento filosófico mais inteligente, e também mais relevante sob o ponto de vista educacional, é o defendido por Harré (1986) de que o mundo (isto é, o real) tal como ele é, desempenha um papel indispensável na gênese do nosso conhecimento embora dele só possamos experienciar aspectos limitados [recupera-se aqui uma das teses caras ao realismo crítico que conhecidos físicos da chamada escola de Copenhague desenvolveram no quadro da Filosofia da Ciência (ver, por exemplo, Niels Bohr, 1963)]. Recupera-se igualmente que, aquilo que num dado momento não passa de um construto, pode vir (ou não) a revelar-se como realmente existente (foi o que aconteceu, por exemplo, no caso dos vírus, moléculas ou galáxias... até serem cientificamente observáveis). Ou seja, para Harré, tratase de não alienar, pura e simplesmente, a idéia central do mundo como princípio regulador e de nos apropriarmos da História da Ciência para o debate epistemológico/ontológico. Ao contrário do construtivismo epistêmico de Glasersfeld anteriormente referido, não se estabelece uma ruptura entre o epistêmico e o ontológico; pelo contrário, a ênfase passa a ser no explorar das articulações dinâmicas entre tais vertentes. $\mathrm{Na}$ Educação em Ciência não se pode ignorar a vertente ontológica, isto é, declarações sobre como é o mundo (questão por certo bem menos relevante no âmbito de outras áreas de estudo como, por exemplo, a Educação em Línguas ou Educação Artística), o modo como se articulam tais declaraçôes com o estudo do que sabemos e o modo como o chegamos a saber (vertente epistemológica).

Mas há mais aspectos muito discutíveis a considerar no construtivismo radical. Com efeito, desde Fernando Pessoa que sabemos que o mundo não é uma idéia minha mas que a minha idéia do mundo é uma idéia minha. O que não é adequado é a desvalorização do papel da comunidade científica no processo de legitimação dessa idéia de mundo e que o construtivismo radical desvaloriza ou ignora mesmo. Ora, sabemos depois de Lakatos (1992) que a verdade científica 
(tentativa, dinâmica) não resulta somente de exercícios de observação resultantes de confrontação com o mundo, mas que incorpora processos de decisão envolvendo a comunidade científica (quem alguma vez submeteu um artigo de investigação para publicação num jornal com arbitragem prévia percebe o argumento). Porventura mais pertinente ainda é a incapacidade de abordagem da questão ética. Na verdade, ao sobrevalorizar a noção de o conhecimento ter de ser viável, isto é, “... adequar-se aos nossos propósitos” (Glasersfeld, 1996), viabilidade que é uma noção nuclear na sua teorização sobre o conhecimento (em desfavor da noção de verdade, ainda que tentativa e provisória), Glasersfeld não dá resposta a questões como a levantada por Fox Keller (ver diálogo com Glasersfeld op. cit.) sobre a situação hipotética de, como físicos, termos sido capazes de (conforme nossos propósitos) inventar armas de destruição completa do mundo! Ou seja, podemos dormir descansados, pois a viabilidade foi assegurada! E não chega contra-argumentar, à guisa de desculpa, que desde os pré-socráticos nenhuma teoria filosófica racional foi capaz de formular uma base para a Ética. Quando se apresentam propostas de mudança (viabilidade em vez de verdade científica) estas devem ser para melhor. As propostas de Glasersfeld podem ser muito interessantes para a Psicologia mas devem ser vistas com cuidado para a Educação em Ciência. Utilizando uma conhecida metáfora da Química Quântica, trata-se de uma transposição “interdita” na fig. 1.

Finalmente, importa sublinhar que a visão dinâmica e saudável da relação entre conhecimento e mundo anteriormente referida não é, e está longe disso, a visão prevalecente que os alunos têm. No essencial, o que prevalece é (continua ser) o realismo ingênuo, em que o conhecimento é (supostamente) a representação estrita de um mundo ontológico externo. Por outro lado, é bem sabido que as imagens que os alunos formam de Ciência têm muito a ver com a visão de Ciência dos seus professores e com o designado currículo oculto (imagens implícitas designadamente nos programas e manuais escolares).

Algumas dessas imagens são conhecidas. Refiram-se as mais pertinentes: (a) uma visão antropocêntrica, isto é o Homem como conquistador e controlador da natureza e não fazendo parte integrante dela; em última análise é por aqui onde se pode ainda pretender legitimar a corrida desenfreada aos recursos naturais e a degradação de sistemas ambientais; (b) cientismo, isto é a deificação da Ciência e da Técnica e suas ilimitadas possibilidades, sobretudo pela utilização do chamado método científico; como refere Máximo Ferreira (2001), “... o desenvolvimento da Ciência foi dando ao homem a confiança de que o entendimento (e a manipulação) da natureza estavam ao seu alcance, fazendo dele como um deus aprendiz"; neste contexto, verdade científica (necessariamente tentativa e dinâmica) confunde-se incorretamente com certeza; (c) o ideal analítico, em que o todo seria melhor compreendido pelo estudo das suas partes, esquecendo-se como nos recorda Morin (1999), a propósito desse princípio de redução, “... como se a organização do todo não produzisse qualidades ou propriedades novas em relação às partes consideradas isoladas". E vai mais longe, ao afirmar que o princípio de redução "... oculta o imprevisto, o novo e a invenção"; o que se separou deve depois ser unido; valoriza-se a causalidade linear, em que se procuram relaçôes simples de causa e efeito ao invés de se terem em conta relaçóes complexas; (d) visão mecanicista do método, levando à crença muito difundida da existência de um método linear e único de se chegar à verdade científica, em desfavor do pluralismo metodológico; (e) realismo ingênuo (a que já nos referimos) em que as idéias científicas seriam a reprodução precisa da natureza, fazendo tábua rasa de todo o processo de idealização e de imaginação criadora, necessariamente presente na construção do conhecimento científico (gases ideais, soluções ideais, pontos materiais, pêndulos ideais, deslocamento sem atrito...), atos de criatividade que só lhe acrescentam mais valias como empreendimento humano; (f) ausência de dimensão axiológica, isto é, uma componente pela qual se propicia o desenvolvimento da tomada de consciência ética e, em particular, de uma 
ética de responsabilidade. A interpelação ética, a reflexão sobre os valores que está na sua essência, deve estender-se à Ciência escolar. As responsabilidades da Tecnociência, bem como dos cientistas, não podem continuar a ser escamoteadas pela Ciência escolar.

Tais aspectos devem ser inteligentemente integrados no processo de ensino/aprendizagem como uma importante valência. E é nesse sentido que a Unesco aconselha a que o ensino das ciências deve incluir ética da ciência, bem como formação em história, filosofia e sobre o impacto cultural da ciência (Unesco, 1999). Também a American Association for the Advancement of Science (AAAS) propõe que “... estudantes educados numa perspectiva liberal - quer se trate de "majors" quer de não "major" - devem completar os seus cursos de ciências de forma a poderem apreciar a ciência como uma parte da nossa tradição intelectual, social e cultural. Os cursos de ciências devem valorizar estes aspectos da ciência enfatizando as dimensões ética, social, econômica e política" (AAAS, 1989). A dificuldade de o fazer não pode servir de desculpa à resignação. Menos ainda de continuar a passar uma visão neutral da Ciência através do currículo oculto. Assim, por exemplo, a relação do cientista com o seu tempo, que o conhecimento da História da Ciência proporciona, afigura-se um elemento relevante no âmbito de uma cultura científica em que o ensino dos valores na Educação em Ciência não é alienado. A adequada exploração de biografias de homens e mulheres da Ciência (Einstein, Galileu, Marie Curie...), o valor das suas descobertas e invençôes, a contextualização delas, o segmento posterior da utilização dessas descobertas, o confronto entre propostas de intenção que originalmente continham e a posterior utilização que lhe foram dadas, exercita o espírito crítico dos alunos, estimula-os a usar o pensamento lógico e a explorar procedimentos científicos e suas inter-relações com os valores da ética. Simultaneamente, propicia o desenvolvimento da escolha pessoal de valores no percurso da construção do ser-se cidadão ou cidadã eticamente vinculado(a) e a saber melhor compreender e atuar no continuum de possibilidades que a Tecnociência oferece. Mas não só isso. Também permite uma melhor compreensão do cientista como pessoa. Como refere Holton (1998), “... a mundovisão de um cientista é certamente tão importante como o domínio das ferramentas matemáticas necessárias à sua atividade. Estou a pensar na confissão de Einstein, na qual reconhecia a influência que sobre ele tiveram as leituras de David Hume \& Ernest Mach, ou na profunda crença de Milikan na realidade dos átomos, a despeito dos ensinamentos anti-atomísticos do seu orientador de doutoramento, Michael Pupin”. Estamos ainda longe destes ventos de mudança.

\section{Orientação no 2 - Dimensão contextualizada}

A designação de Ciência contextualizada pretende sublinhar que, sendo dirigida para todos, tem de dizer respeito a assuntos que potencialmente lhes interessem.

Para os alunos mais jovens, Hodson (1998) sugere o estudo de temáticas do tipo: "Eu e a Ciência" (por exemplo, o estudo dos sentidos); "Ciência em casa" (por exemplo, estudo de materiais naturais e sintéticos, reciclagem, segurança em casa); "Ciência e ambiente" (por exemplo, fauna e flora local, Astronomia, clima); "Ciência no trabalho" (por exemplo, biotecnologia, telecomunicações); "Ciência e tempos livres" (fotografia, estudo de peças tecnológicas simples, como o funcionamento de brinquedos). A abordagem que aqui se defende, para estes temas (em particular no ensino básico) vai ao encontro do proposto por Fensham (1985) ao envolver o estudo de tais assuntos com interessantes contextos de partida e como cerne das aprendizagens e não só, como é mais vulgar, em termos de contextos possíveis de aplicação de princípios científicos.

A orientação curricular de Ciência contextualizada é muitas vezes desvalorizada com o argumento que não é suficientemente acadêmica. Tal argumento é duplamente despropositado. 
Primeiro, porque ela não é dirigida para a formação de especialistas. Segundo, porque o grau de sofisticação e enriquecimento de saberes que o estudo de alguns desses assuntos permite é muito variável. Por exemplo, saber para quê e como usar um dado fusível numa instalação elétrica caseira é um bom meio para se aprender algo sobre eletricidade (dimensão Ciência), para promover a auto-estima do aluno através de aprendizagens com êxito e ligando o saber com o saber fazer (dimensão pessoal) e, ao mesmo tempo para, eventualmente, precaver situaçóes de perigo para o próprio e para os outros (dimensão social).

Contextualizar implica valorizar, em primeiro lugar, a conceitualização das situações, o que exige cuidados no estudo qualitativo das mesmas. A questão não é desvalorizar o quantitativo nem o disciplinar. Bem pelo contrário. É perceber quáo importante ele é, mas em diálogo com o qualitativo. Ou seja, tratá-lo de outra maneira. O caso da Física é particularmente pertinente pois sucede freqüentemente que problemas de Física se transformam em problemas de Matemática, isto é, perde-se o sentido qualitativo (físico) da situação em estudo (embora o resultado apareça com tantas casas decimais quantas as permitidas pela máquina de calcular do momento).

Para os alunos mais velhos, temas como o estudo do Cosmos, Sistemas de Informação e Comunicação, Meio Ambiente, Energia, Novos Materiais ou Biologia Molecular, Princípios de Conservação e o estudo de problemáticas interdisciplinares a elas associadas, recolhem um grande consenso. Assim, por exemplo, o estudo de Sistemas de Informação e Comunicação poderia permitir uma abordagem interdisciplinar envolvendo saberes da Bioquímica, da Física, das TIC e até aspectos das Ciências da Linguagem. Não se trata, aqui, de desvalorizar as disciplinas como categorias essenciais de organização do conhecimento científico (não pode haver interdisciplinaridade nem transdisciplinaridade sem um conhecimento profundo das disciplinas de partida). Pelo contrário, trata-se de as valorizar através do combate à sua coisificação e do estabelecimento de novos laços de solidariedade entre elas, mas não só.

É importante que as problemáticas a estudar não sejam, ou não sejam só, assuntos do passado mas sim também com marca de contemporaneidade, dado que a finalidade de uma Educação em Ciência para a cidadania tem de prever o estudo de problemáticas recentes. Não é demais de sublinhar este aspecto. Tal implica um grande esforço de atualização e disponibilidade científica dos professores para fazerem leituras inovadoras do currículo (que tem de perder o caráter prescritivo e de controle e passar a ser lido como um documento de referência, de índole dinâmica e, por isso mesmo, sujeito a melhoramentos e com algum grau de flexibilidade). Por exemplo, no âmbito do estudo dos materiais, tem sentido um estudo qualitativo e interdisciplinar da supercondutividade e das implicaçôes e aplicaçôes atuais desta descoberta (que não sendo recente, só há bem pouco tempo começou verdadeiramente a ser explorada). A mesma coisa para o genoma humano. Estes assuntos não podem ser deixados para o estudo sofisticado do ensino superior onde a grande maioria dos alunos não terá oportunidade de os estudar. Devem ser abordados antes, e de forma certamente diferente da que é feita na Física do estado sólido ou da Biologia molecular. São demasiado importantes para serem deixados para as elites científicas. Se assim for, o fosso entre os poucos que sabem muito e os muitos que sabem pouco vai-se alargando.

A Ciência é sempre sobre qualquer coisa. O que significa que é tão discutível usar o trabalho experimental simplesmente para ilustrar conceitos (que provavelmente podem ser aprendidos mais vantajosamente de outro modo) como usá-lo para desenvolver competências em abstrato. Qualquer alternativa deve pois envolver de um modo ou de outro o diálogo complexo e nunca acabado entre saberes conceituais e metodológicos; o trabalho experimental, nos seus vários formatos, é um instrumento privilegiado. 
No entanto, continua a haver alunos que atravessam a escolaridade obrigatória sem terem tido a oportunidade de realizar uma só experiência! Menos ainda são os eleitos que foram envolvidos em algum pequeno percurso de pesquisa e tiveram a oportunidade de reconhecer quão difícil é descobrir algo de novo (para eles, naturalmente), a complexidade de um planejamento (ainda que à sua escala), a subida de auto-estima em face de uma experiência com sucesso ou a frustração de um resultado não expectável. Ou seja, a ênfase do trabalho experimental deve ser centrada no aluno e, se possível, envolvendo algum tipo de pesquisa. Hoje em dia, em Portugal, em boa parte como resultado do programa Ciência Viva, não é por falta de equipamento que se não faz trabalho experimental nas escolas. A questão é outra. Tem sobretudo a ver com a sua falta de valorização a nível curricular e com a falta de tempo para desenvolver percursos de pesquisa devido à extensão dos currículos (quando é que se levará a sério que "menos pode ser melhor"?).

\section{Orientação no 3 - Dimensão Sócio-Construtivista}

A decisão de escolhermos uma orientação construtivista (senso lato) tem a ver com ser esta a melhor alternativa a uma visão ainda dominante de ensino das Ciências centrada no modelo de transmissão/recepção, por nós considerado inadequado. Importa, no entanto, referir que, até ao momento, a orientação construtivista (senso lato) foi bem mais promissora para a pesquisa em ensino das Ciências do que para o ensino das Ciências (qualquer que seja o nível de ensino). Tal discrepância ilustra bem o pouco impacto da pesquisa educacional nas práticas de ensino.

De acordo com Philips (1995) “... o construtivismo tornou-se qualquer coisa parecida com uma religião” e Rodriguez (1998) refere que “... há mais de 20 anos, o construtivismo tem sido uma "epistemologia guarda-chuva" abarcando um vasto corpo de pesquisa em educação em ciência". E acrescenta que "... Pfundt and Duit (1991) compilaram uma bibliografia contendo mais de 1100 estudos orientados segundo quadros teóricos de referências construtivistas. No entanto, existem várias perspectivas construtivistas a que correspondem diversas terminologias".

Não é nossa intenção desenvolver aqui uma análise do construtivismo como importante referencial para a pesquisa educacional e para a prática de ensino e formação. Vários estudos de revisão sobre o assunto (ver p. ex. Geelan, 1997; Steffe and Gale, 1995; Phillips, 1995) debruçam-se sobre a natureza e características de diferentes perspectivas do construtivismo. Por exemplo, Geelan (1997), propõe um esquema para organizar as diferentes perspectivas de construtivismo e respectivos autores de referência segundo dois eixos: social/pessoal e objetivista/relativista, levando a quatro combinaçóes possíveis.

Independentemente da forma discutível como diversos autores tentaram racionalizar a diversidade do campo de estudo, é importante reconhecer tal esforço de clarificação. $\mathrm{O}$ construtivismo é um conceito multifacetado e alberga várias correntes que nem sempre são coerentes É, pois, importante que se esclareça qual a perspectiva de construtivismo que se defende já que hoje em dia o uso desta designação é feito sem qualquer rigor. Se não desfizermos essa ambigüidade corremos o risco de dar à luz (mais) um chavão pedagógico.

No âmbito deste trabalho, a perspectiva de construtivismo que nos interessa defender em relação à aprendizagem tem a ver com o nosso entendimento da aprendizagem como processo social e culturalmente mediado. Ou seja, estamos, no essencial, a valorizar a compreensão de situações e contextos sócio-culturais em que a aprendizagem tem lugar e do modo como esta é influenciada por tais situações e contextos. Estamos, nomeadamente, a falar de Vygotsky (1962, 1978), embora (pelo menos) outros autores (ainda que com ênfase diferente) devam ser referidos em relação a esta orientação sócio-construtivista como, por exemplo, Bakhtin (1981) e Lave \& Wenger (1991).

Vygotsky, ao contrário de Piaget, preocupa-se essencialmente com a aprendizagem e a influência do ambiente social e cultural nos processos de aprendizagem. Para ele, a direção essencial 
do desenvolvimento não vai do individual para o social mas do social para o individual. De um processo de natureza interpessoal passa-se progressivamente para um processo de natureza intrapessoal. Sem deixar de reconhecer a importância fundamental da atividade individual, destaca que o indivíduo progride pela apropriação da cultura através das interaçôes sociais, cuja vivência favorece a sua interiorização. Tal interiorização corresponde à reconstrução interna de uma operação externa e, nesse sentido, para Vygotsky, o desenvolvimento é uma sócio-construção. A influência positiva das interaçôes sociais nas aprendizagens cognitivas foi experimentalmente demonstrada pelos investigadores da corrente da Psicologia Social, particularmente no que respeita ao papel do conflito sóciocognitivo no êxito das interaçōes mostrando a importância dos confrontos entre pares.

Vygotsky considera que o conflito se gera num processo de interação social sendo resultante de um confronto entre idéias de diferentes sujeitos, o que lhe confere uma dimensão interpessoal, chamando-lhe então conflito sociocognitivo. Para Vygotsky, a atividade do sujeito é fundamental, enquanto processo de transformar o meio mediante o uso de instrumentos, destacando dois tipos de mediadores: as ferramentas que atuariam diretamente sobre os estímulos e os signos ou símbolos que modificam o próprio sujeito e, através deste, os estímulos. É a cultura que proporciona ao indivíduo as ferramentas de que necessita para modificar o seu meio, adaptando-se ativamente a ele. A cultura é constituída por sistemas de símbolos que medeiam as nossas açōes, sendo a linguagem o sistema de signos mais utilizado. A linguagem tem um papel essencial pois, além de ser um instrumento do pensamento, é um fator de desenvolvimento do próprio pensamento ao funcionar como instrumento de mediação psicológica entre os indivíduos e a realidade onde se inserem. E também é do ponto de vista intrapsicológico ao possibilitar a reflexão pessoal, a fala interna do sujeito, construindo as respostas que vão sendo necessárias e desenvolvendo a consciência. Os sistemas de signos são formados por conceitos e estruturas organizadas de conceitos. Os significados (mediadores simbólicos) são proporcionados pela cultura, pelo meio social. Há, porém, que os internalizar, o que implica uma série de processos psicológicos. A aprendizagem consiste, precisamente, na internalização progressiva de instrumentos mediadores, iniciando-se no exterior por processos que só depois se transformam em processos de desenvolvimento interno. Para Vygotsky, e contrariamente a Piaget, o desenvolvimento dependeria da aprendizagem (o que não quer dizer que qualquer aprendizagem seja possível em qualquer momento). Mais especificamente, a aprendizagem passa a ser uma condição de desenvolvimento desde que se situe na designada "zona de desenvolvimento próximo" (ZDP) e que representa a diferença entre aquilo que o aluno é capaz de resolver por si só (em geral através da resolução de problemas) e aquilo que ele só é capaz de fazer sob a orientação de outros, professor ou colegas mais capazes. Para Vygotsky "a instrução de qualidade é aquela que precede o desenvolvimento" (idem). A ZDP é um construto central na teoria da mediação de Vygotsky e representa "uma medida do potencial de aprendizagem; representa a região na qual o desenvolvimento cognitivo ocorre; é dinâmica, está constantemente mudando" (Moreira, 1999). "O limite inferior da ZDP é fixado pelo nível real de desenvolvimento do aprendiz. $\mathrm{O}$ superior é determinado por processos instrucionais, no ensino formal ou informal" (idem). O professor potencia assim as aquisiçôes do aluno promovendo a transição de uma atividade tutelada para uma atividade autônoma. Uma das conseqüências educacionais da noção de ZDP é de que se deve orientar o ensino das ciências para os chamados objetivos de desenvolvimento e não somente para objetivos mínimos (de que a infantilização de algumas atividades propostas aos alunos é um bom exemplo). Outra consequiência, esta já em termos de metodologias de ensino, é a de privilegiar estratégias de pesquisa e de que a resolução de problemas (que não tem de ser só de papel e lápis) é uma parte integrante. Mais do que propor exercícios interessa, pois, propor aos alunos tarefas problemáticas e explorar adequadamente as interaçôes entre os alunos Falta, porém, conhecer melhor que intervenção didática a "zona de desenvolvimento próximo" possibilita e que modalidades de organização do tutorado (pelo professor) ou mentorado (por outros alunos) são mais eficazes em termos de aprendizagem. 
De notar que Vygotsky dedicou particular atenção à aprendizagem de conceitos e às relações entre conceitos espontâneos (senso comum) e científicos. A aquisição de conceitos espontâneos tem por base abstraçōes realizadas sobre os próprios objetos, mas, a aquisição de conceitos científicos parte do sistema de conceitos existente. Este argumento revela pois uma posição que contesta frontalmente a perspectiva de aprendizagem por descoberta no ensino das ciências. Um conceito científico só adquire significado pela sua relação com outros conceitos implicando processos de reestruturação ou reorganização do sistema conceitual. O que exige uma consciência reflexiva.

Para Vygotsky o conhecimento conceitual do aluno resulta da interação entre o conhecimento comum ("intuitive knowledge") e o conhecimento a que tem acesso via instrução ("school knowledge"), no caso que nos interessa a ciência escolar, interação que pode seguir três caminhos diversos. Ao transpor estas idéias para o ensino das ciências, Cachapuz (1995) refere que, "o primeiro tem a ver com a sua (do aluno) própria visão do mundo natural e é de natureza privada; o segundo resulta de interpretações feitas por outros, i.e. comunidade científica e a que o aluno tem acesso via (sobretudo) professor e/ou manuais escolares". É por isso, por exemplo, que a teoria sobre a deriva dos continentes não cabe dentro da Geologia do sensível já que nenhum aluno pode observar tal deriva. As diferenças não param por aqui. $\mathrm{O}$ conhecimento comum é construído na base do que o aluno acredita, enquanto que o conhecimento veiculado pela escola é marcado pela autoridade (professor e/ou manuais); o primeiro processa-se sem limites de tempo e de forma não sistemática, enquanto que, no segundo, há não só limitações temporais de acordo com o calendário escolar mas também saberes dispersos de acordo com uma organização disciplinar; o primeiro, não é suposto ser demonstrado, enquanto que, no segundo, há expectativas de avaliação; o primeiro valoriza uma lógica de atributos e o segundo uma lógica de relações. Devido à natureza de tais atributos, Vygostky sugere três vias diversas que o processo de interação entre conhecimento comum e conhecimento científico pode seguir (por simplicidade aqui encaradas isoladamente):

- Situação de convergência: a integração faz-se sem problemas; tudo se passa como que uma diferenciação por continuidade, da realidade pessoal para uma perspectiva mais lata e sistemática. Por exemplo, sensações vividas pelo aluno, como a evaporação do álcool sobre a sua pele ou do seu suor após exercício físico, permitem-lhe uma apropriação, em geral, não problemática da noção de transformação endotérmica (ainda que sob outra designação menos técnica).

- Interação simbólica: é o que acontece quando se propõe ao aluno o estudo de um novo domínio conceitual, como, por exemplo, molécula, eletronegatividade, cromossomo, ...; neste caso, a integração é facilitada já que uma das componentes (conhecimento comum) é minimizada. O que não significa que a aprendizagem se faça necessariamente sem problemas, mas devido agora ao caráter eventualmente abstrato das novas idéias ou falta de pré-requisitos conceituais ou metodológicos do aluno.

- Situação de conflito: neste caso, conhecimento comum e conhecimento científico apresentam-se ao aluno como eventualmente contraditórios. A integração é difícil e pode nem sequer ter lugar. Assim se explicam estratégias de estudo freqüentemente usadas pelos alunos levando à aprendizagens rotineiras (decorarem a resposta certa). Dado ser no ensino básico onde tem lugar a introdução de um grande número de modelos teóricos das Ciências, é previsível que seja também aí onde situações de conflito sejam mais pertinentes. Por exemplo, quando da abordagem da fotossíntese (ensino básico), são vulgares idéias sobre a mesma como uma forma de "respiração ao contrário", que teria lugar de dia, enquanto que a segunda se processaria de noite; ou, 
ainda, de que as plantas retirariam diretamente do solo (através das raízes) os seus alimentos não se lhes reconhecendo o estatuto de produtores" (Cachapuz, 1995).

Registre-se, de passagem, que o exame atento das propostas de Vygostky sobre a interação entre conhecimento do senso comum e conhecimento científico pode lançar novas luzes sobre a fundamentação psicológica das designadas concepções alternativas dos alunos que, como projeto de investigação, só surgiu em meados dos anos 70.

Para Vygostky, o significado de um dado conceito (ou situação) é resultante da interação com os outros (professor ou alunos), mediada através da linguagem que é o meio pelo qual se estimula os alunos a refletirem e explicarem, de modo a compreenderem, como é que as suas experiências e o seu conhecimento contextualizado se integram num sistema mais amplo. Valoriza-se, pois, a vida social na classe, as interações variadas, bem como o papel mediador do professor na construção de conhecimento dos alunos. Há todavia, ainda, que compreender melhor como se articulam as dinâmicas sociais e individuais no desenvolvimento cognitivo.

A linguagem tem aí uma função fundamental mas não a que lhe é predominantemente atribuída durante a escolarização, isto é, a de instrumento de comunicação. A função da linguagem que importa valorizar, segundo Vygotsky, é a de um instrumento de aprendizagem, o que implica desde logo a valorização da relação intersubjetiva (necessariamente solidária) dos alunos sobre uma dada situação do mundo em estudo, como ponto de partida para a construção do conhecimento. Não é difícil reconhecer que este argumento vai na esteira do (último) Wittgenstein (1958) para quem só podemos avaliar da coerência do nosso discurso através de normas reconhecidas intersubjetivamente. E é através da escola que o aluno pode aprender o que não pode experienciar diretamente. No nosso entender, o essencial das idéias de Vygotsky está por explorar quer no ensino quer na formação de professores.

\section{A CONCLUIR}

Como refere McMurray (1975), "uma das idéias centrais da teoria educacional é de que a influência de propostas de ação depende de acreditarmos ou não (e em que extensão) na sua relativa validade". Para que se possa promover uma mudança de perspectiva no que respeita ao ensino das ciências, necessário se torna que os professores:

- acreditem que a mudança é possível;

- possam formar uma representação coerente da inovação pretendida.

Dado que o modo como se ensina as Ciências tem a ver com o modo como se concebe a Ciência que se ensina, e o modo como se pensa que o Outro aprende o que se ensina (bem mais do que o domínio de métodos e técnicas de ensino), torna-se pertinente aprofundar aspectos tendo em vista a formação epistemológica dos professores bem como aspectos relativos à concepção de aprendizagem. É da nossa experiência como formadores de professores e como investigadores que tais vertentes da formação são tradicionalmente obstáculos para o entendimento de Ciência, de Educação em Ciência e de ensino das Ciências que aqui se defenderam.

Sem a pretensão de definir uma agenda, refiram-se dez pontos críticos cuja alteração é necessária na Ciência escolar que temos:

- ensino das Ciências que começa demasiado tarde e termina demasiado cedo, não se inserindo numa perspectiva de aprendizagem ao longo da vida; 
- ensino das Ciências fortemente marcado por uma visão positivista da Ciência e, em boa parte por isso mesmo, sobrevalorizando contextos acadêmicos (Ciência como retórica de conclusôes) onde são quase sempre ignoradas articulaçôes essenciais C/T/S/A (Ciência/Tecnologia, Ciência/Sociedade, Ciência/Ambiente) ou ainda Ciência/Ética ajudando a situar culturalmente a Ciência no quadro de uma educação para uma cidadania responsável;

- ensino das Ciências quase só tendo lugar em ambientes formais (escola) não explorando sinergismos com a comunidade científica, trabalho de campo, clubes de Ciência, visitas a centros de investigação, instalaçôes industriais, centros de Ciência, museus de Ciência...;

- ensino das Ciências sub-valorizando (de fato) o desenvolvimento de competências e atitudes científicas (por exemplo, quando se passa dos programas propostos à avaliação das aprendizagens, muitas são simplesmente ignoradas em prol da avaliação do "corpo de conhecimentos";

- ensino não experimental (apesar de recentes e corajosas iniciativas no quadro do programa Ciência Viva);

- ensino das Ciências onde o uso pelos alunos das novas tecnologias da informação e comunicação como recurso didático é praticamente simbólico;

- ensino das Ciências onde a interdisciplinaridade e a transdisciplinaridade estão ausentes;

- ensino das Ciências onde o caráter transmissivo asfixia o investigativo;

- ensino das Ciências onde se burocratizaram as funções do professor, a começar pela ritualização da avaliação da aprendizagem;

- ensino das Ciências privilegiando a extensão e não a profundidade nas abordagens programáticas (confusão entre "cumprir" o programa e promover a excelência das aprendizagens).

Assim sendo, não é de estranhar que muitos alunos, demasiados alunos no nosso entender, não se entusiasmem pelo estudo das Ciências, não encontrem aí terreno fértil para desenvolver a sua curiosidade natural, não percebam sequer para que é que vale a pena estudar Ciências (excetuando o objetivo utilitário de se saírem bem nos exames).

É este o sentido da nossa contribuição no campo da Educação em Ciência, enquanto espaço de reflexão e de ação para uma qualidade de Educação que os tempos reclamam e que assumimos como um compromisso político e ético.

\section{Referências}

ABIMBOLA, I. The relevance of the new philosophy of science for the science curriculum. School Science \& Mathematics, Menasha, v. 83, n. 3, p. 181-192. 1983.

AMERICAN ASSOCIATION FOR THE ADVANCEMENT OF SCIENCE. Project 2061: science for all Americans. Washington, DC: AAAS. 1989.

BAKHTIN, M. M. The dialogic imagination: four essays. Austin: University of Texas Press. 1981.

BOHR, N. Essays of atomic physics and human knowledge. New York: John Wiley, 1963. 
CACHAPUZ, A. O ensino das ciências para a excelência da Aprendizagem. In: CARVALHO, A (Org.). Novas Metodologias da Educação. Porto: Porto Editora, 1995. p. 350-385.

; PRAIA, J.; JORGE, M. Ciência, educação em ciência e ensino das ciências. Lisboa: Ministério da Educação, 2000.

et al. A emergência da didática das ciências como campo específico de conhecimento.

Revista Portuguesa de Educação, Braga, v. 14, n. 1, p. 155-195. 2001.

CHASSOT, A. Alfabetização científica: questões e desafios para a educação. Ijui: Ed. da Unijui, 2000.

COLLINS, H. A comunidade científica em tempos de disputa. In: GIL, F. (Coord.). A ciência tal qual se faz. Lisboa: Sá da Costa, 1999. p. 53-64.

FENSHAM, P. J. Science for all: a reflective essay. Journal of Curriculum Studies, Basingstoke, Inglaterra, v. 17, n. 4, p. 415-435. 1985.

FERREIRA, M. Jogos inacabados. Jornal de Letras: artes e idéias, Lisboa, n. 17, mar. 2001.

FOUREZ, G. La constrution des sciences. Bruxelles: De Boeck University, 1995.

GEELAN, D. Epistemological anarchy and the many forms of constructivism. Science \& Education, New York, 1997. p. 615-28.

GLASERSFELD, E. Constructivism, the psychology of learning, and the nature of mathematics: some critical issues. Science \& Education, New York, n. 2, p. 87-93. 1993.

A construção do conhecimento: em novos paradigmas, cultura e subjectividade. Porto Alegre: Artes Médicas, 1996. p. 75-92.

HARRÉ, R. Varities of realism. Oxford: Blackwell, 1986.

HODSON, D. Teaching and learning science. Buckingham: Open University Press. 1998.

HOLTON, G. A cultura científica e os seus inimigos: o legado de Einstein. Lisboa: Gradiva. 1998.

LAKATOS, I. History of science and its national reconstructions. In: WORRAL \& CURRIE (Eds.). The methodology of scientific research programmes. Cambridge: Cambridge Univiversity Press, 1992.

LAVE, J.; WENGER, E. Situated learning: legitimate peripheral participation. Cambridge: Cambridge University Press. 1991.

MCMURRAY, F. Concepts of mind and intelligence in educational theory. Educational Theory, Urbana, n. 25, p. 234-242. 1975. 
MILLAR, R. Towards a science curriculum for public understanding. School Science Review, London, v. 77, n. 280, p. 7-18, 1996.

MILNER, B. Why teach science and why to all? In: NELLIST \& NICHOL (Ed.). The ASE Teachers Handbook. 1986. p. 1-10.

MOREIRA, M. Teorias de aprendizagem. São Paulo: EPU. 1999.

MORIN, E. Os sete saberes necessários à educação do futuro. São Paulo: Cortez 1999.

OSBORNE, B. Science Education: a concise review of the past thirty years. Perspectives, n. 45, p. 6-13. 1992.

PFUNDF, H.; DUIT, R. Bibliography: students' alternative frameworks and science education. 4 ed. Kiel, Germany: Institute for Science Education at the University of Kiel, 1991.

PHILLIPS, D. The good, the bad, and the ugly: the many faces of constructivism. Educational Researcher, Washington: American Educational Research Association, v. 24, n. 7, p. 5-12, 1995.

RAMONET, I. La tyrannie de la communication. Paris: Gagilée, 1999.

RODRIGUEZ, A. Strategies for counterresistance: toward socio transformative constructivism and learning to teach science for diversity and for understanding. Journal of Research in Science Teaching, New York, v. 35, n. 6, p. 589-622, 1998.

SHAMOS, M. The myth of scientific literacy. New Brunswick, NJ: Rutgers University Press, 1995.

STEFFE, L.; GALE, J. (Ed.). Constructivism in education. Hillsdale, NJ: Erlbaum, 1995.

UNESCO. Ciência para o século XXI: um novo compromisso. Lisboa: Comissão Nacional da Unesco, 1999.

VROOM, V. Work and motivation. New York: John Wiley, 1964.

VYGOTSKY, L. Thought and language. Cambridge: MIT Press, 1962. . Mind and society. Oxford: Blackwell, 1978.

WITTGENSTEIN, L. Philosophical investigations. London: Blackwell, 1958.

ZIMAN, J. A ciência na sociedade moderna. In: GIL, F. (Coord.). A Ciência tal qual se faz. Lisboa: Sá da Costa, 1999. p. 437-450. 